\title{
CORREDOR-MATHEOS Y EDWARD HOPPER (CON CARMEN MARTÍN GAITE AL FONDO). HABITACIÓN DE HOTEL
}

\author{
CORREDOR-MATHEOS AND EDWARD \\ HOPPER (WITH CARMEN MARTÍN GAITE \\ TO THE BACKGROUND). HOTEL ROOM
}

\section{LAUREANO BONET \\ Universidad de Barcelona}

\begin{abstract}
Resumen: El cuadro de Edward Hopper Habitación de hotel dejó honda huella en José Corredor-Matheos y Carmen Martín Gaite, pertenecientes al mismo grupo generacional aunque con usos estilísticos dispares. Su reacción ecfrástica ante este óleo vendría facilitada por el hecho de que Hopper fue un "pintor para literatos», según lo confirman las numerosas recreaciones poéticas y narrativas de sus cuadros. En el poema "Qué soledad aflige» (2007), Corredor-Matheos se acerca a Habitación de hotel por medio de una escritura ajena a cualquier señuelo mimético, resaltando la abstracción y esencialidad del cuadro: una tensión helada. Por su parte, Martín Gaite — cuyo realismo es subjetivo y emocional— psicologizará este lienzo en «Todo es un cuento roto en Nueva York» (1993) y en la conferencia Hopper. Habitación de hotel (1996). Pese a dicha disparidad escritural, anida en ambos autores una misma respuesta: el ser humano malvive en un mundo inhóspito, que le intensifica la soledad, la angustia y la alienación.
\end{abstract}

Palabras clave: Edward Hopper; Habitación de hotel; José Corredor-Matheos; Carmen Martín-Gaite; écfrasis; Michael Riffaterre; abstracción; esencialismo; psicologización.

Aвstract: The picture of Edward Hopper Hotel Room left a deep mark on José Corredor-Matheos and Carmen Martín Gaite, belonging to the same generational group although with different stylistic uses. His ecfrastic reaction to this oil would be facilitated by the fact that Hopper was a "painter for writers», as confirmed by the numerous poetic and narrative recreations of his paintings. In the poem "Qué soledad aflige» (2007) Corredor-Matheos approaches Hotel Room by means of a writing outside of any mimetic temptation, highlighting the abstraction and essentiality of the painting: an icy tension. For her part, Martín Gaite -whose realism is subjective and emotional - will psychologize this canvas in «Todo es 
un cuento roto en Nueva York» (1993) and in the conference Hopper. Habitación de hotel (1996). Despite this scriptural disparity, the same response nests in both authors: the human being lives in an inhospitable world, which intensifies loneliness, anguish and alienation.

KeY words: Edward Hopper; Hotel Room; José Corredor-Matheos; Carmen MartínGaite; ecphrase; Michael Riffaterre; abstraction; essentialism; psychologization.

El presente artículo está nutrido por diversas paradojas, discordancias y, a la vez, por un motivo central que las amansa un poco, concediéndoles cierta cohesión. Por un lado, tenemos a dos escritores pertenecientes a la generación del medio siglo (no se olvide que José Corredor-Matheos nace en 1929 y Carmen Martín Gaite cuatro años antes), que encarnan dos idiolectos literarios muy dispares, según iremos observando (con lo que se diluye el concepto, más o menos arbitrario, de «generación literaria»).Y, por otro lado, esos contrastes o divergencias, sin desaparecer del todo, dialogarán entre sí gracias a un cuadro que ha seducido largo tiempo a CorredorMatheos y Martín Gaite: Habitación de hotel (Hotel Room), el óleo sobre lienzo de 152,4 por 165,7 centímetros que Edward Hopper concibió en 1931, una de las joyas del Museo Thyssen-Bornemisza de Madrid.

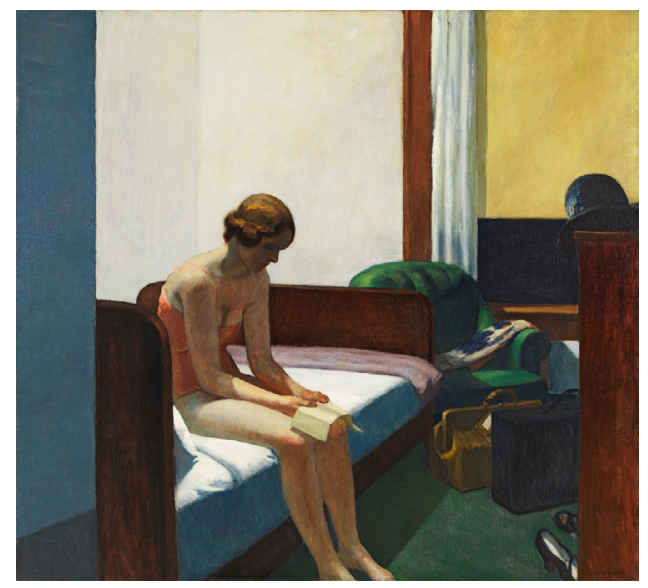

Edward Hopper, Habitación de hotel (1931).

(Procedencia: Museo Thyssen-Bornemisza). 
Literatura y artes plásticas, pues, frente a frente: ut pictura poesis. La mutación — acaso la reinvención- de Hotel Room mediante la escritura; esto es, la écfrasis y sus vaivenes entre la «reflexion sur l'Autre», u objeto pictórico, y «l'expression du moi», o sujeto contemplador (Riffaterre, 2002: 202) ${ }^{1}$. Los colores, los barnices, los aceites de esta tela se recomponen, por tanto, en una nueva materialidad constituida ahora por sonidos, palabras y múltiples combinaciones oracionales. O dicho sea en frase algo sentenciosa: el cuadro será escrito por el observador que lo analiza con gran afán, provocando una explosión emocional en su mente... El engarce entre lo icónico y lo literario lo constituirán (en el caso de José Corredor y Martín Gaite) la figura femenina y su entorno espacial, que emanan de esas manchas pictóricas diseminándose por Habitación de hotel: una muchacha solitaria, a medio desvestir, sentada al borde de una cama, en una minúscula alcoba perteneciente quizás a un hotel de Nueva York. No se olvide que, a la manera de Delacroix en el siglo XIX, Hopper es también un pintor para literatos — acaso un pintor en parte «literario»— y ello porque sus personajes y arquitecturas despiertan en el espectador extrañeza, desasosiego, seducción, impulsándole a inventar mil historias $^{2}$. Conforme ha escrito uno de los principales estudiosos del arte

Se trata, pues, de una suerte de hipotiposis encaminada a describir con ánimo vivaz algo o a alguien; en nuestro caso, un objeto plástico. Hecho significativo: tal figura intermediadora "cherche à rivaliser» con el arte pictórico (Morier, 1989: 528). Aprovecho esta nota para agradecer a José Corredor-Matheos las numerosas noticias literarias que, con generosidad y paciencia, me ha ofrecido estos últimos meses, agradecimiento que extiendo también a los profesores Sofia González Gómez, Gail Levin y Fernando Valls. Gracias a todos ellos ha logrado, creo, llegar a buen fin este artículo, que nace de una breve conferencia que ofrecí en el homenaje a nuestro poeta organizado por la Asociación Profesional de Escritores de Cataluña el 11 de noviembre de 2012, en el Ateneu Barcelonès. Ahora bien, el presente trabajo amplía sobremanera los contenidos de aquella disertación, añadiéndole más matices, más reflexiones y, asimismo, nuevos textos críticos referentes tanto a Edward Hopper como a José Corredor y Carmen Martín Gaite.

2 El culto por Edward Hopper anida en un buen número de escritores, en un amplio sentido hispánico. En España contamos, aparte de José Corredor-Matheos y Carmen Martín Gaite, con Irene Sánchez Carrón, Antonio Jiménez Millán y Ernest Farrés (este último el más hopperiano de todos ellos), sin olvidarnos, claro está, de la uruguaya Cristina Peri-Rossi, creadora del intenso poemario Habitación de hotel. En la literatura norteamericana la presencia del pintor es 
de Hopper, sugiriendo tal dialéctica entre la quietud, o parálisis, que destila una imagen congelada y el ansia del espectador por descubrir lo que hay detrás de dicha elipsis, el creador de Nighthawks (Halcones de la noche, o Noctámbulos) paraliza en sus lienzos

the narrative that constitutes a drive in an automobile or the montage of a movie to focus on strangely isolated stills. Seen by themselves, these stills are mysterious and haunting. They evoke a desire for the rest of the narrative, and they powerfully convey the break-up of the storyline, the disjunction that is characteristic of modern life. In this manner they awaken in the viewer a desire for the whole, and thus elicit feelings of isolation and loss. The feelings of loneliness experienced by viewers of Hopper's art, who sometimes use the term "desolation» to describe that they see, come from the fact that a continuum has been broken (Hobbs, 1987: 16).

El de Hopper es un arte plástico que nace de sucesivos contrastes entre lo inmóvil y lo dinámico, la foto fija y el relato en ciernes, aunque libre de toda excitación melodramática, sea visual, auditiva u olfativa. El griterío, los ruidos, la suciedad, las pestilencias no se adivinan en Hopper, incluso en sus obras más urbanas, a diferencia, pongo por caso, de los cityscapes neoyorkinos pintados por su coetáneo George Bellows. Y solo en muy raras ocasiones puede asomar el esguince grotesco, la caricatura muñequil, en algún óleo temprano, como Soir Bleu, o en Two Comedians, el lienzo que cierra la carrera de nuestro artista, dos años antes de su fallecimiento en 1967. Se trata de una pintura, en fin, elusiva y alusiva y que, como tal, incita a los espectadores a rellenar lo omitido en ella y a urdir, en su imaginación, un relato ya móvil, activo, similar a la estrategia

destacable en Stephen King, David Ray, Mark Strand, Paul Auster y, sobre todo, Joyce Carol Oates. Por otro lado, Gail Levin ha realizado una pesquisa de las lecturas de Hopper a lo largo de su vida y, ciertamente, nos encontramos ante un pintor literario, pese a que sus declaraciones sobre tales lecturas fueran siempre muy escuetas. Sus autores preferidos van de Shakespeare y Cervantes a Thomas Mann, Robert Frost o Hemingway, pasando por Goethe, Ralph Waldo Emerson, Herman Melville, Proust, Freud y George Santayana. Destaca esta estudiosa que el realismo esencialista, o metarrealismo, es rasgo muy de nuestro pintor — quien leyó con atención el Quijote-, habida cuenta de que su realismo «like that of Cervantes, is itself a kind of fiction. Just as Cervantes posed questions about the nature of fiction itself, Hopper painted seemingly precise locations that he actually synthesized from multiple places to create a kind of meta-realism» (Levin, 2018: 127). 
del iceberg promovida por Ernest Hemingway ${ }^{3}$. De ahí también la distancia tan glacial que logra componer Hopper en sus mejores cuadros: piénsese nuevamente en Nighthawks, óleo de 1942, y con alguna que otra analogía con "The Killers», el admirable cuento de Hemingway, casi sobra recordarlo. Un texto sobre el que Hopper, tras haberlo leído en Scribner's Magazine en marzo de 1927 (revista donde él mismo había colaborado en calidad de dibujante), confiesa por escrito a su editor:

It is refreshing to come upon such an honest piece of work in an American magazine, after wading through the vast sea of sugar coated mush that makes up most of our fiction. Of popular prejudices, the side stepping of truth, and of the ingenious mechanism of the trick ending there is no taint in this story (en Levin, 1998: 350).

\section{EDWARD HOPPER, LA ABSTRACCIÓN DE LA FIGURA PICTÓRICA}

De acuerdo, pues, con lo dicho por Robert Hobbs, se deduce que los óleos y dibujos hopperianos son islotes metonímicos alusivos a la vida estadounidense en la primera mitad del siglo $\mathrm{xx}$, sea esa vida urbana o rural: un escenario gélido, unos seres absortos y, no pocas veces, oprimidos por arquitecturas en absoluto indulgentes y que nuestro artista suele también enfriar acentuando en lo posible lo geométrico, síntoma de la implacable abstracción a que somete a los seres, las cosas, los espacios internos o externos ${ }^{4}$. En un cuadro tardío como Sun in an Empty Room, esa abstracción de lo real alcanzará su máxima intensidad, y el espacio, ahora, es insensible frente a cualquier pálpito emocional, al tiempo que se percibe un pleno ascetismo en el tratamiento de las formas y los colores. Mark

3 Puede calificarse a Hopper de «cazador del instante fugitivo» que, como tal, logra confinarlo dentro de un cuadro (Martín Gaite, 1997: 18). Más tarde el contemplador-literato pondrá, efectivamente, en acción ese instante por medio de la escritura.

4 En Hopper, efectivamente, el «vacío comunicativo» entre los personajes «se refuerza con un vacío ambiental». Y ello hasta el punto de que en sus pinturas —desde un ángulo ahora técnico- «las masas de color [...] chocan unas contra otras, sin mezclarse jamás» (Combalia, 1981: 10). 
Strand (poeta norteamericano inserto en la misma cala generacional de Corredor-Matheos) dirá que este lienzo transmite «una visión del mundo sin nosotros; no solo un lugar que nos excluye, sino un lugar vaciado de nosotros» (Strand, 2008: 107) ${ }^{5}$.Y según anota ahora Milton W. Brown, acentuando aún más esas reflexiones a medias formalistas, psicológicas e historicistas,

[1] a América de Hopper es un país ingrato. Él no le encuentra ningún calor a las calles, ni a las casas, ni a sus habitantes; y la luz siempre tan pródiga no calienta nunca. Situados en un contexto urbano o rural, sus personajes son siempre extraños, solitarios, anónimos, habitantes provisorios de lugares inhospitalarios... Solo son símbolos de una vida dolorosa (en Marí, 1981:2).

Pero, antes de pasar a examinar la recreación literaria que hicieran de Hotel Room Corredor-Matheos y Martín Gaite, puede resultar útil ofrecer, a modo de contraste, el testimonio de Josephine Nivison, «Jo», esposa de Hopper y modelo para este y otros muchos cuadros suyos. Se trata de una descripción tecnicista, sin apenas hacer referencia a lo anecdótico, y en la que se enfatiza, sobre todo, la presencia de los colores (ausentes en José Corredor y muy sobrios en Martín-Gaite, conforme iremos viendo):

Pintado en el estudio de N[ueva]Y[ork]. Habitación de hotel. Una muchacha alta con camisa rosa, pelo castaño, leyendo un folleto de horarios (amarillo). Fuera es de noche, la luz proviene de arriba. Alfombra verde, un sillón ancho verde, la persiana amarilla. A los pies de la cama una manta color lavanda. Maleta negra y bolso marrón. Sombrero y zapatos negros. Las paredes muy blancas, excepto la que está en

Podríamos, por tanto, deducir que la pintura de Hopper es un supremo ejemplo de realismo abstracto, donde impera el geometrismo como forma activadora del lienzo. Mark Strand estima que el «trapecio isósceles» constituye la "figura favorita» de este artista, a la vez «imperativo formal» $\mathrm{y}$ «remisión a la fatalidad» (Strand, 2008: 26 y 89). Tal figura sobresale, poderosa, en Nighthawks, mientras que en Hotel Room se visualizan, especialmente, «frágiles líneas verticales y horizontales» (Strand, 2008: 91).

6 Con cierto paralelo con esas líneas razonará, por su parte, Carmen Martín Gaite que «[Hopper] estuvo libre de “ideas".Lo que le atrajo [...] fueron ciertos temas que se repiten: personajes solitarios en habitaciones desnudas, restaurantes, teatros; puentes y azoteas deshabitados» (Martín Gaite, 2005: 151). 
sombra en el extremo izquierdo, en un azul grisáceo turbio, de superficie más oscura (en Bozal, 2012: 21-22).

\section{JOSÉ CORREDOR-MATHEOS Y LA AFLICCIÓN DE LA SOLEDAD}

El poema de Corredor-Matheos lleva por título su primer verso, "¿Qué soledad aflige», y está encabezado en la esquina derecha de la página con la leyenda en cursiva "Ante el cuadro "Habitación de hotel", de Edward Hopper».Apareció inicialmente en Un pez que va por el jardín (2007), y fue luego reimpreso en Desolación y vuelo. Poesía reunida (2011). Ha comentado nuestro poeta: «No recuerdo cuándo escribí esta composición, aunque debió ser cuando vi Habitación de hotel por primera vez en la Thyssen, entre 2005 y 2007».Y se trata de una pintura que revisita "por lo menos dos veces al año» cuando va a Madrid, anotando además que descubrió a Hopper «en la sección de USA de la Bienal Hispanoamericana de Arte, en 1955, cuando todavía faltaban bastantes años para que me dedicara a la crítica de arte. Se trataba de Cinema en Nueva York, que me impresionó mucho. En esta obra aprecié la misma sensación de soledad que en Habitación de hotel» ${ }^{7}$.

Se trata de un poema compuesto por veintidós versos, heptasílabos combinados con versos de cuatro y cinco sílabas, sin rima salvo dos versos cruciales (el 19 y el 20).Y en recurso estilístico muy de José Corredor, se dejan ver también los encabalgamientos suaves, blandos, las paradojas que moderan cualquier sequedad silogística o el uso de la derivación léxica, esto es, la repetición de una misma palabra con diferentes morfemas flexivos ${ }^{8}$. Por ejemplo, los versos octavo y décimo - asimismo capitales en el devenir del poema-, a propósito de la mujer del cuadro: «y no parece estar / a punto de marcharse. / Como está estamos todos». En fin, esta composición,

7 Correo electrónico a Laureano Bonet, 7 de octubre de 2019.

8 Sobre el cuestionamiento del racionalismo a ultranza por medio de constantes esguinces paradójicos — rasgo muy visible en su poesía más madura—, ha dicho Corredor: «El racionalismo está relacionado con una visión superficial de la realidad y esteriliza la visión. Prescinde de otras potencias humanas absolutamente imprescindibles, como la intuición, con la apertura a lo desconocido» (en Bonet, 2019: 33).Véase también, en torno a esta cuestión, la nota 12. 
hermosa y austera, sin halagos retóricos, se desarrolla toda ella del siguiente modo:

\author{
¿Qué soledad aflige \\ a la mujer del cuadro? \\ Tiene aún las maletas \\ por abrir, \\ como las tengo yo. \\ No acaba de volver \\ de sitio alguno, \\ y no parece estar \\ a punto de marcharse. \\ Como está estamos todos: \\ ignorantes, \\ colgados en un tiempo \\ y un espacio \\ que no pueden ser nuestros. \\ No hay soledad que pueda \\ compartirse, \\ y esto es lo que la aflige \\ y nos aflige. \\ Saber que estamos solos, \\ y que no estamos solos, \\ y es más profunda así \\ la soledad \\ (Corredor-Matheos, 2011: 443).
}

En ese discurrir de los versos se vislumbra una movilidad dramática — si bien nada física — que va alcanzando más y más pesadumbre, por medio de una creciente comunión entre la mujer del cuadro y los sucesivos yoes que van poblando el poema': el yo autoral que observa dicha pintura e inmediatamente los múltiples, anónimos yoes que integran la condición humana, siendo consciente CorredorMatheos de que esa soledad, por ser plural, es más "profunda». El

9 Asistimos a un discurrir, esto es, una narratividad en ningún caso física, salvo los cuatro primeros versos, los cuales, aunque sea de manera oblicua, hacen referencia al cuadro hopperiano, la muchacha que lo protagoniza y el equipaje por abrir. Es una écfrasis, pues, en movimiento, dado que la escritura literaria implica una sucesión de palabras engarzadas unas con otras y que van creando, por tanto, una secuencia temporal, llámese esta poema o relato. Si bien, como ya se ha dicho, Hopper impulsará aún más en el espectador ese discurso narrativo, al ofrecer sus lienzos una inquietante mezcla entre congelamiento, ocultación y fragmentarismo. 
verso decisivo que facilita tal fusión entre la muchacha solitaria de Hopper y la muchedumbre de yoes es el décimo, «Como está estamos todos», un verso a simple vista muy sencillo pero que supone una perspicacia creacional poco común. Como frase comparativa de igualdad que es, se transformaría en el habla cotidiana con el sintagma, ciertamente anodino, «Está como estamos todos». Ahora bien, José Corredor hace una levísima alteración en el orden de la frase, resituando el adverbio como al inicio del enunciado, con lo que se enfatiza esa soledad compartida entre la mujer del cuadro, el yo autoral y una multitud de seres anónimos.

Por otra parte, y desde un ángulo acústico, la categoría verbal está (con acentuación aguda) resalta la soledad que sufre la mujer hopperiana. Parece trocear el verso en dos mitades - lo hace momentáneamente- - pero a la postre ambas mitades se funden, creándose un clima semántico que, conviene reiterarlo, denota que esa soledad de una mujer anónima, casi aplastada por la arquitectura de una minúscula alcoba, es, en rigor, la soledad de todos nosotros. En fin, un ligero hipérbaton y un acento agudo que levanta el sonido de la sílaba alcanzan a destilar — en un verso situado por el centro del poema - una insólita expresividad. La forma se convierte, pues, en mensaje, y ello de manera muy fluida, sin la menor traba.

\section{EL POEMA, UN DESDOBLAMIENTO AUTORAL}

Frente a otras piezas de Corredor-Matheos en las que reina el reposo, la quietud —el instante eternizado ${ }^{10}$ —, este homenaje a Hopper va, al contrario, deslizándose verso tras verso, hasta fijar un cierto itinerario con visos de soliloquio mental — a saber, una indagación cuyo primer paso es una pregunta muy precisa y que, como tal, reclama con urgencia respuesta-; un itinerario en cierto modo circular, puesto que la composición comienza y acaba con el mismo vocablo: soledad. Pero no se trata de una circularidad en absoluto plana, pues

10 Me inspiro aquí en J.V. Foix — tan admirado por Corredor-, quien declaró en una ocasión que «en el poeta tiene lugar una lucha constante entre los instantes y el Instante. Este último nos pone en contacto con la eternidad» (en Bonet, 1962: 8). Una eternidad, pues, depurada de escorias convencionales: la esencia en su plenitud. 
se va ahondando poco a poco en el sentir existencial —el dolor de la vida- que constituye la esencia tanto del cuadro hopperiano como de este espectador-creador que conocemos con el nombre de José Corredor-Matheos ${ }^{11}$. Por un lado, está la pregunta inicial: «¿Qué soledad aflige a la mujer del cuadro?».Y por otro, culminando ya el poema: «Saber que estamos solos, / y que no estamos solos, / y es más profunda así / la soledad». Nótese que esta voz, soledad, cierra en efecto nuestra pieza y, al tener acentuación aguda, provocará una súbita expansión sonora vibrando en medio del silencio que nace tras la lectura de dicho poema: un énfasis fónico y, al tiempo, conceptual.

Un par de observaciones más, antes de avistar a Carmen Martín Gaite.Algún crítico ha alegado que esta pintura de Edward Hopper casi es un pretexto, o acicate, para la materialización del poema correderiano, dado que esos versos serían una «reflexión abstracta sobre la soledad en general» y, con ello, «el texto se aparta del cuadro, que puede verse, así, como excusa o punto de partida para el desarrollo textual de una idea» (Ema Llorente, 2018:13) ${ }^{12}$. Quizá esta estudiosa haya desdeñado, en mayor o menor medida, la abstracción de la materialidad pictórica que lleva a término el propio Hopper, según se apuntó atrás, y que, justamente, es lo que atrapa a Corredor, el cual confesará: «Me atrae especialmente ese cuadro porque, siendo realista, es muy abstracto. Tiene el tema de la soledad reducido a lo esencial.Y lo esencial de los creadores me atrae porque es a lo que mi poesía aspira» ${ }^{13}$.

El poema, así, absorbe dicha abstracción esencialista, la hace suya por medio de los signos plásticos que constituyen la materialidad del lienzo. No hay, por consiguiente, polarización alguna entre esa materialidad externa y la esencialidad interna: jugar con estos dos enunciados conllevaría un engaño conceptual. De esta forma, el poema no rehúye el cuadro. Lo confirman, además, los impresionantes versos centrales, que alcanzan a verbalizar el geometrismo temporal y

11 La «preocupación — si no angustia - existencial» es poco frecuente en la poesía corredoriana de la década de 1960, pero empezará a manifestarse a partir de Carta a Li-Po (Vega-Sampayo, 2008: 94).

12 Parece acercarse María Ema Llorente al razonamiento de Michael Riffaterre alusivo a que la écfrasis literaria de una pintura implica, por fuerza, el sacrificio de esta última, convirtiéndola en excusa para que tome cuerpo la «projection de l'écrivain», superponiéndose así el «texte écrit [...] sur le texte visuel» (Riffaterre, 1994: 221).

13 Correo electrónico a Laureano Bonet, 7 de octubre de 2019. 
espacial que comprime a esa mujer hopperiana (un cubículo hotelero del año 1931): «Como está estamos todos: / ignorantes, / colgados en un tiempo / y un espacio». Elena Vega-Sampayo, a diferencia de María Ema Llorente, sí apunta la ligazón existente entre el poema correderiano y la pintura de Hopper, revelando el ancla léxica que los aúna, precisamente la forma verbal colgados, inserta en tales versos:

El instante atemporal del alojamiento en un hotel retratado
en el cuadro se convierte en una afirmación absoluta: «Como
está estamos todos: / [...] / colgados en un tiempo / y un
espacio». El cuadro está físicamente así, colgado en un museo
durante un tiempo, de manera similar a la que una lectura co-
loquial del metafórico "colgados» parecería aplicarse por igual
a la mujer del hotel que aparece en el cuadro y a todos los
miembros del género humano (Vega-Sampayo, 2008:94-95).

Hemos sugerido ya que ese texto corredoriano, tan meditativo, da cuenta de la contemplación de Hotel Room por parte del yo autoral ${ }^{14}$. Ello parece colisionar con alguna de las premisas del grupo literario Seix Barral, sobre todo la referente a que el creador empírico del poema irá extinguiéndose conforme dicho poema vaya cristalizando en forma de cuerpo textual cada vez más indiferente a los iniciales designios de aquel. Por ello, no podría hablarse de una comunicación abierta, sincera, entre las emociones previas del autor y los nuevos sentimientos surgidos de una obra con vida propia ya. Como es bien sabido, así lo plantearon Gabriel Ferrater y Jaime Gil de Biedma a la luz de T. S. Eliot, quien, en un artículo que vio la luz en The Egoist entre septiembre y diciembre de 1919, había dejado escrito, a propósito del poeta en plena acción creadora, que este hecho «is a continual surrender of himself as he is at the moment to something which is more valuable. The progress of an artist is a continual self-sacrifice, a continual extinction of personality» (Eliot, 1969: 17).

Pues bien, Corredor-Matheos cuestionará por entero tal propuesta racionalista, casi «científica» —en términos estéticos ${ }^{15}$ - al declarar con actitud enteramente ajena al Modernism occidental:

14 Corredor-Matheos «ha llevado a término una obra poética, de enorme altura, que se confunde con la meditación y, en cierto modo, con la plegaria» (Duque Amusco, 2019: 34).

15 Argüirá el creador de The Waste Land: «It is in this despersonalization that art may be said to approach the condition of science» (Eliot, 1969: 17). Esa hinchazón 
no distingo el poeta como persona del poeta como autor del poema, sino que sitúo a los dos en el proceso del poema. No creo en absoluto lo de que, como escribió Pessoa, el poeta sea un fingidor. No creo que Eliot, a quien admiro mucho, tuviera razón en punto tan esencial. Tierra baldía, que me gusta mucho, es, sin embargo, un ensamblaje cubista demasiado voluntario quizá, en parte, por culpa de Ezra Pound. Por otra parte, Rilke, al que admiro aún más, es el otro extremo. Mi caso es, en cierto modo, opuesto a los dos. Supongo que me viene, sobre todo, de mi interés por el budismo y también por otros métodos de perfección espiritual. Al escribir el poema, me desdoblo. Se trata de un distanciamiento en el que te ves escribiendo. Al hacerlo así te distancias de ti mismo y puedes llegar a percibir que tú no eres el que crees ser, sino Otro. Los hinduistas dicen: «Tú eres eso» ${ }^{16}$.

\section{CARMEN MARTÍN GAITE Y LA PSICOLOGIZACIÓN DE LO PICTÓRICO}

Centrándonos, finalmente, en Carmen Martín Gaite, su querencia por Habitación de hotel no es menos intensa que la experimentada por José Corredor-Matheos. Acaso obsesiva, dado que la atraparía por entero en la etapa última de su vida, desde el otoño de 1980 (cuando descubre a Hopper en una retrospectiva neoyorkina) hasta 1996, momento en que ofrece su conferencia El punto de vista, consagrada

tecnológica de lo literario entrará en crisis cuando hacia 1970 empiece a desangrarse el mito de la razón pura, realzándose ya otras lindes estéticas, hijas de una sensibilidad esquiva ante los valores occidentales. Tiene lugar, pues, un cambio de brújula estética que, en España, vendría avalado por los primeros ensayos de Fernando Savater y Xavier Rubert de Ventós, sin olvidar los textos que J. Á. Valente reunió en Las palabras de la tribu (1971). No menos reveladora fue la creación de la editorial Kairós por Salvador Pániker a mediados de los años sesenta, consagrada a la espiritualidad oriental. Lo acreditarán firmas de la talla de Alan Watts (El gran mandala, 1971) y Thomas Merton (El Zen y los pájaros del deseo, 1972), éxitos punteros en el catálogo de este sello. El poemario del propio Corredor Carta a Li-Po (1969-1975) será otro síntoma de este giro cultural: se abre con los versos, que socavan la poesía entonces vigente, «Escribir un poema / que nada signifique» (Corredor-Matheos, 2011:139). Pero no se olvide que la «nada» — según escribiera Fridugisus de Tours a Carlomagno- «es algo inmenso y noble» (1995: 3; la versión castellana es mía).

16 Correo electrónico a Laureano Bonet, 22 de octubre de 2019. 
a Hotel Room. Pese a que existen otros muchos textos suyos alusivos a este cuadro, nos detendremos sobre todo en unos párrafos de tal disertación, leída el 14 de diciembre 1996 en el Museo Thyssen de Madrid - aunque sin obviar un poema previo que se nos antoja crucial- Esta conferencia constituye, en suma, la síntesis definitiva de lo que nuestra novelista había escrito desde aquel otoño de 1980, en su primera estancia en Nueva York, ciudad que la deslumbró y asustó a partes iguales.

¿Cuál es la hipótesis que va hilando Martín Gaite a propósito de Hotel Room y en el decurso de casi veinte años? La respuesta no deja lugar a dudas: una visión física, nada abstracta ahora, donde la experiencia estética se aúna con el autobiografismo. Entiende que Edward Hopper es un artista imprescindible para adentrarnos en el corazón de la sociedad americana, muy en particular por sus espacios urbanos más perturbadores. El propio pintor había confesado en 1959 la mezcla de sentimientos y tentaciones plásticas que le imbuía acercarse a una metrópoli: «I've always been interested in approaching a big city by train», pues ello implica «a certain fear and anxiety, and a great visual interest in the things that one sees coming into the city» (en Mamunes, 2011: 8).

A ese respecto, Habitación de hotel ejercería para Martín Gaite un papel a la par metonímico y vicario, repleto de ingredientes psíquicos al tiempo que estéticos: un ejercicio ecfrástico, por lo tanto, que desencadena múltiples tensiones entre lo referencial (el texto icónico) y lo autorreferencial (la subjetividad del espectador/escritor $)^{17}$. Tal cuadro «es» Nueva York y en su superficie se materializa también el estado anímico de la autora-contempladora: soledad, extrañeza ante una urbe que, vuelvo a subrayar, le atrae y le inquie$\mathrm{ta}^{18}$. Hasta tal punto le fascina este óleo que en su diario Visión de Nueva York, compuesto en 1980, dejará claro: «Yo misma soy ahora

17 La acción ecfrástica se entiende, en suma, como un conjunto dinámico de «alteridades [...] en las relaciones yo/otro, texto/imagen» (Bongers, 2016: 49).

18 En contraste con Martín Gaite, Joyce Carol Oates plasma en su recreación ecfrástica de Nighthawks - y mediante una enunciación en tercera persona- un bullicio de monólogos que desarrollan los cuatro personajes de este lienzo, reunidos a media noche en un diner de Nueva York, monólogos que se mezclan entre sí hasta constituir una telaraña de historias fragmentarias, conviviendo todas ellas con imágenes procedentes de dicho recinto. Destaca, sobre todo, el soliloquio de la mujer y su percepción de la noche como tiempo inmóvil: «The woman is wearing / a short-sleeved red dress cut to expose her arms / [...] / it's the middle of the night and she has a feeling / time is never going to budge. 
como la mujer de un cuadro de Hopper, mientras siento un poco de melancolía y desarraigo» (Martín Gaite, 2005: 140).Y en avenencia con esa psicologización pictórica imagina un «poema narrativo» cuya protagonista, tras recorrer Manhattan, se refugia en el lienzo de Hopper, sentándose en una cama de este hotel, sin esperar ya «nada», momento con el cual culmina dicha composición, titulada «Todo es un cuento en Nueva York», y que fluye así:

Sin abrir tan siquiera la maleta, acaba de quitarse los zapatos porque los pies le duelen, y se ha quedado sola entre cuatro paredes, condenada a aguantar a palo seco esa luz de la tarde ya en declive que se filtra en la estancia veteada de brillos engañosos, con los brazos caídos y la mirada estática, clavada eternamente de cara a una ventana que de tan bien pintada parece de verdad (Martín Gaite, 1993: 92).

Tales versos son, en mayor o menor medida, buen ejemplo de la écfrasis literaria según la entiende Michael Riffaterre y que consistiría en «une lecture», pues

ce qu'elle déchiffre $[\ldots]$ ce n'est pas le tableau, c'est celui qui le regarde. C'est l'interprétation du spectateur (de l'auteur) qui dicte la description, et non le contraire. Au lieu de copier le tableau [...], l'ekphrasis l'imprègne et le colore d'une projection de l'écrivain, ou mieux du texte écrit, sur le texte visuel (Riffaterre, 1994: 221).

El poema de Martín-Gaite, a diferencia del arte hopperiano (y de los versos correderianos), está henchido de ruidos, luces, sombras, gentío, bullicio callejero, a través de una dispersión de imágenes que logra capturar el caos de la urbe moderna en una larga secuencia casi cinematográfica — lo filmico es voz referencial que aparece en algún verso $^{19}$ - . Lo denotan, pongamos por caso, estos sintagmas reuni-

[...]. She's still contemplating / the cigarette burning in her hand» (Oates, 1989: $40-41)$.

19 «[...] una silueta, vaga, fugaz y discutible / que llevabais soñada en la retina / tal vez porque la visteis en un film [...]» (Martín Gaite, 1993: 91). Esa gradual 
dos un poco al azar: «los anuncios, los locos, los cubos de basura», «resplandores de gris y amarillo», "parpadeo de semáforo», «sorteando autobuses», «papeles arrugados, desperdicios, colillas», «borbotones de agua sucia», «estridencias y empujones» o el perturbador «susto de pájaro nocturno» (Martín Gaite, 1993: 88-92) ${ }^{20}$.

En su disertación de 1996 desliza asimismo Martín Gaite una serie de pensamientos en parte más eruditos, más fríos, a tono con su oficio de escritora y con la capacidad del arte hopperiano por generar literatura: una síntesis, en rigor, de sus experiencias estéticas y psíquicas ante las pinturas del norteamericano ${ }^{21}$, muy especialmente ante Habitación de hotel, que define como un cuadro que «es [...] novela él mismo» (Martín Gaite, 1997: 18).Y, por ello, aviva en el espectador el deseo de crear más y más narraciones, coincidiendo pues, en mayor o menor medida, con la interpretación que del arte hopperiano hiciera Robert Hobbs, según vimos ya. Puestos en esta tesitura, ¿cuál será el relato que concibe la escritora salmantina? Con sus mismas palabras, aunque abreviándolas aquí y allá:

Lo primero que sugiere [Habitación de hotel] es que esa mujer está de paso en una ciudad que no conoce. [...]. Es de noche, está cansada y nada le ha salido bien. Se ha quitado parte de la ropa [...] y se inclina en una postura incómoda, con el rostro ensombrecido y los ojos bajos, fijos en un papel amarillo que tiene entre las manos. El equipaje no ha llegado a abrirlo, la ropa la ha puesto sobre una butaca verde y el sombrero, verde también, un casquete de los años veinte, reposa sobre el único mueble impersonal del conjunto, un rectángulo alargado de la misma madera oscura de la cama. [...]. Pasa el tiempo — porque el tiempo hacia la madrugada se siente transcurrir en este cuadro-y ella sigue sin moverse ni tomar decisión alguna. El mueble, aunque tuviera cajones,

expansión de imágenes, chocando unas con otras, parece remitir a Paterson, de William Carlos Williams, poeta al que la autora dedica sus versos (Carmen Gaite, 1993: 88).

20 ¿Levísima huella de Nighthawks?

21 Ahora bien, se trata de una conferencia con el sujeto autoral nada escondido y, por ello, ajena a las frialdades de una disertación académica, aun cuando nuestra escritora despliegue una muchedumbre de noticias y citas relacionadas con Hopper. El resultado es un texto, por consiguiente, ensayístico y en el que las precisiones, las agudezas y una suerte de microrrelatos van alternándose a lo largo de las páginas, deudoras - habrá ya advertido el lector- de «Todo es un cuento en Nueva York» y, desde luego, del diario Visión de Nueva York. 
no le van a hacer falta, porque nada hace conjeturar que la viajera vaya a quedarse a dormir en esa habitación anónima. $Y$ la angustia fluye como una riada.

La mujer es joven. No sabemos - y tal vez ella tampocolo que ha venido a hacer en la ciudad. [...]. Se pregunta, ¿para qué habré venido? Y se quiere ir, pero es de noche cerrada, los conserjes están dormidos, la ciudad es una selva peligrosa [...]. De toda la pintura iluminada por esa claridad fría de la luz eléctrica del techo se desprende una sensación fuertísima de incomunicación, soledad y anonimato. La desazón de los viajes sin designio (Martín Gaite, 1997: 20-22).

\section{HOPPER, CORREDOR-MATHEOS, MARTÍN GAITE Y EL SER EN EL MUNDO}

José Corredor-Matheos y Carmen Martín Gaite experimentan dos reacciones muy dispares frente a un mismo cuadro en cuanto a la enunciación poético-narrativa ${ }^{22}$. Nuestro poeta, en pos de la esencia que se esconde en las bellas artes y en los seres humanos: la brevitas como su rasgo creacional más genuino, habida cuenta de que «[1] a espontaneidad me obliga con frecuencia a reducir, y raras veces a desarrollar» (Corredor-Matheos, 2019: 60). Una poesía de la renuncia y la meditación, sin la menor duda: sus versos son, por encima de todo, «versos que piensan»(Doce, 2010: s. p.) ${ }^{23}$. Martín

22 Señala Corredor: «El realismo, en el arte, si se entiende como reproducción del mundo que suponemos conocido no me interesa. El arte creo que ha de hacernos ver lo desconocido, secreto, misterioso [...]. La vida y ese mundo que creemos conocer son una cosa y la creación artística, otra. El arte egipcio antiguo, al igual que el griego, era al principio muy abstracto y evocaba los personajes fuera del tiempo y el espacio. Podemos hablar de visibilia ex invisibilia. En el egipcio, avanzado del Imperio nuevo, se pueden reconocer en los retratos de personajes las enfermedades que tenían: son plenamente realistas en el sentido de reproducción del mundo real. Y con el griego, a partir de la mitad del siglo quinto antes de Cristo, ocurría lo mismo. Se pierde la intemporalidad de los Kouros y las Korés y aparecen retratos fieles a lo real cotidiano, que aunque puedan ser de una gran belleza no son verdaderas creaciones ni van más allá de lo visible, sin adentrarse, pues, en el misterio de lo verdaderamente real» (Correo electrónico a Laureano Bonet, 7 de octubre de 2019).

23 Poesía ciertamente reflexiva, por la que se derrama, vivificador, el silencio, y desnuda además de cualquier estridencia cromática: lo esencial al desnudo. En cita de Ramón Xirau — tan afín a Corredor — : «la palabra entraña silencio y el silencio palabra. [...] El silencio esencial es el que está en la palabra misma como 
Gaite, por su parte, transita por las sendas del relato literario, al amparo de un realismo en absoluto impávido, antes bien quebradizo, fantasioso, con ciertos toques kafkianos ${ }^{24}$. La amplificatio, en este caso, como recurso más propio del arte de la novela, y donde imperan las señales deícticas, tanto espaciales como temporales, rehuyendo así cualquier abstracción.

Corredor-Matheos y Martín Gaite presentan disonancias estilísticas muy notorias, sin duda alguna, pero a la vez varias analogías léxicas favorecidas por ese doble mirar que se posa en Habitación de hotel, y todas ellas para resaltar la soledad que aqueja a la protagonista. En el poema de Corredor-Matheos, la voz soledad surge ya en el primer verso y reaparecerá en el verso 15 para, luego, cerrar la pieza. Asimismo, diversas cláusulas afines irán apuntalando esa conciencia de desamparo: «la aflige», «nos aflige» o «estamos solos». En su poema, por consiguiente, bulle lo dramático, si bien limpio de cualquier histrionismo retórico, tal como ocurre con las pinturas de Hopper. En el texto de Martín Gaite, la floración léxica que va dibujando dicha percepción de soledad, tan disfórica, es más vasta y recurrente: «tristeza», «rostro ensombrecido", «desolación», «soledad», «angustia», «selva peligrosa», «noche cerrada», «incomunicación»o «mueble impersonal».

Ese parentesco fraseológico genera, a la luz de Hotel Room, una similar percepción del ser humano como criatura indefensa, dolorosa, en nuestros dos escritores: no se observa aquí contraste alguno. Comparten una visión nada complaciente y que, en un sentido más bien amplio, podría calificarse de existencialista o, mejor, existencial, apelativo que, hecho muy revelador, está hoy reapareciendo en la literatura y en los medios de comunicación, connotando

[...] en su morada; es el silencio que expresa: el silencio que, dicho, entredicho, visto, entrevisto, constituye nuestro hablar esencial» (Xirau, 1993: 144 y 146).

24 Contrasta, aquí, con la impavidez que exhibe la pintura hopperiana —una de sus señas de identidad-, según he sugerido ya. La propia novelista traza un paralelo entre Hopper y algunos autores de la Lost Generation en esa mirada atenta y, a la par, lacónica del mundo que le rodea. Nuestro pintor es «una mirada. Una mirada que se cuela por las paredes.Y de la misma manera que algunos narradores norteamericanos de su tiempo tienden a contar historias en las que ellos mismos no parecen estar implicados $\mathrm{y}$, sin embargo, se nota que han visto todo aquello de lo que hablan, la mirada testimonial de este pintor, por mucho que pretende él esconderse [...], da fe de una presencia absoluta, penetrable e indiscutible» (Martín Gaite, 1997: 13-14). 
'conflictividad', 'confusión', 'incertidumbre' o 'inseguridad'25. Algún analista cree también notar este rasgo en Edward Hopper, quien al describir «the pain and loneliness of the urban man, [...] does not deal with the subjectivity of individuals, but in the distant and empty way of existing in the cities in which they are existentially tossed» (Araujo, 2012: s. p.).

Se percibe una total coincidencia, pues, con aquella interpretación de Mark Strand, citada más arriba, de que el arte hopperiano transmite la percepción de un universo que no solo "nos excluye» sino que está "vaciado de nosotros»: la alienación pura y dura. O por decirlo con unas viejas - y muy actuales- palabras de Martin Heidegger: la angustia que uno percibe al «ser ahí», o «ser en el mundo» - dasein-, como experiencia inhóspita y que, en rigor, significaría "no estar en su casa»: un mundo ajeno a nuestros sentires más íntimos (Heidegger, 1980: 208).Y no cabe olvidar, a ese respecto, que en la poesía última de Corredor-Matheos «el ser [se anuda] con el estar», pudiendo por lo tanto hablarse de un cierto «esencialismo existencial» (Sala Valldaura, 2009: 333) ${ }^{26}$.

25 Véase, por ejemplo, este texto periodístico: «Entre nacionalistas, populistas y movimientos antiinmigración, la Unión Europea se enfrenta a una sobredosis de problemas existenciales» (Rodríguez, 2018: 30).

26 En Martín Gaite el existencialismo es «un hilo, notable eso sí, entre otros muchos que formaron su tejido literario» (Lindström Leo, 2009: 22-23). Confesaría nuestra novelista que La nausée de J. P. Sartre la dejó «alucinada», al leerla en 1948 y descubrirle «la amenazadora» presencia de "ese fondo sombrío» que se oculta en la vida (Martín Gaite, 1993: 328). Rememorando, a su vez, José Corredor alguna lectura existencialista por la década del cincuenta, señala: «de Sartre leí su teatro - Las moscas, muy en particular-y, de Camus, me interesó La peste. Ahora bien, la tesis existencialista centrada en que somos unos seres destinados a la muerte, me resulta poco satisfactoria puesto que, para mí, el existir nos lleva a la trascendencia, según puede adivinarse incluso en Heidegger. Todo eso lo expreso mejor, creo, en este poema que escribí el 31 de diciembre del pasado año: “¿Estás solo? / No estás. / O acaso en un filo / tan agudo y cortante / como es el tiempo. / Y crees vivir, / pero no estás. / Qué claro, el aire. / Qué luminoso, el día. / Todo lo ves de lejos / y cada vez más claro"» (Correo electrónico a Laureano Bonet, 10 de enero de 2020). 


\section{BIBLIOGRAFÍA}

Araujo, Paulo Roberto Monteiro de (2012). «Edward Hopper and Heidegger:The Unveiling of Solitude», Karpa Journal, 5.1 (Summer) - 5. 2 (Winter). [https://www. calstatela.edu/misc/karpa/Karpa5.1/Site\%20Folder/monteiroaraujo1.html]

Bonet, Laureano (1962). «J.V. Foix. "La realidad ha ido más allá de la poesía y, por desgracia, no nos damos cuenta de esto"», Solidaridad Nacional, 11 de octubre, p. 8 (interviú reimpresa, con el título de «J.V. Foix, un investigador de la poesía», en Oh, si prudent $i$ amb paraula lleugera... Entrevistes a J. V. Foix, ed. Margarida Trias, Barcelona, Fundació Foix-Eumogràfic, 2016, pp. 28-31).

— (2019). «Los bucles del tiempo: una conversación con José

Corredor-Matheos», Ínsula [«Dossier: Corredor-Matheos», ed. Sofia González Gómez], 874-875, octubre-noviembre, pp. 29-33.

Bongers, Wolfgang (2016). «Archivo, memoria y écfrasis en la poesía de Gonzalo Millán», en Interferencias del archivo: cortes estéticos y políticos en cine y literatura, Berlin, Peter Lang, pp. 43-62.

Bozal, Valeriano (2012). «El lugar de Hopper», en VV. AA., Hopper,

Museo Thyssen-Bornemisza, Madrid, 12 de junio-16 de septiembre de 2012, Madrid, Fundación Colección Thyssen-Bornemisza, pp. 14-25.

Combalia,Victòria (1981). "Edward Hopper: la solitud del "voyeur"», Quaderns d'Arquitectura i Urbanisme, 147, octubre, pp. 8-11. [https://www.raco.cat/index. php/QuadernsArquitecturaUrbanisme/article/view/198893/297809]

Corredor-Matheos, José (2011). Desolación y vuelo. Poesía reunida, 1951-2011, Barcelona, Tusquets.

- (2013). Sin ruido, Barcelona, Tusquets.

— (2019). «En sus propias palabras. El mar», Ínsula [«Dossier: CorredorMatheos», ed. Sofía González Gómez], 874-875, octubre-noviembre, p. 60.

Doce, Jordi (2010). Perros en la playa (bitácora), 26 de septiembre. [http://jordidoce.blogspot.com/2010/]

Duque Amusco, Alejandro (2019). «Todo en vuelo», Ínsula [«Dossier: CorredorMatheos», ed. Sofia González Gómez], 874-875, octubre-noviembre, pp. 33-34.

Eцıот, T. S. (1969). «Tradition and the Individual Talent», en

Selected Essays, London, Faber \& Faber, pp. 13-22. 
Ema Llorente, María (2018). «Intertextualidad, apropiacionismo e intervención en la poesía española actual», Tonos Digital. Revista de Estudios Filológicos, 35, julio, pp. 1-22. [http://www.tonosdigital.es/ojs/index.php/tonos/article/view/1980]

Fridugisus of Tours (1995). On the Being of Nothing and Shadows (De substantia nihili et tenebrarum), trad. de Paul Vincent Spade, Bloomington, Department of Philosophy, Indiana University. [https://scholarworks.iu.edu/dspace/.../handle/2022/.../fridugis.pdf]

Heidegger, Martin (1980). El ser y el tiempo, trad. de José Gaos, MéxicoMadrid-Buenos Aires, Fondo de Cultura Económica.

Hobis, Robert (1987). Edward Hopper, New York, Harry N. Abrams.

Levin, Gail (1998). Edward Hopper: An Intimate Biography, Berkeley, University of California Press.

— (2018). «Edward Hopper, Literature, and Landscape», Ritsumeikan Studies in Language and Culture, Kyoto, Ritsumeikan University, vol. 29, 4, March, pp. 127-143. [http://www.ritsumei.ac.jp/acd/re/k-rsc/lcs/kiyou/pdf_29-4/lcs_29_4_levin.pdf] Lindström Leo, Ingrid (2009). Scribo ergo sum. Aspectos existenciales en tres novelas tardías de Carmen Martín Gaite, tesis doctoral, Stockholm, Stockholms Universitet. [http:// su.diva-portal.org/smash/record.jsf?pid=diva2\%3A200212\&dswid=-5638].

Mamunes, Lenora (2011). "Approaching a City». Edward Hopper Encyclopedia, Jefferson, McFarland, p. 8.

MARí, Antoni (1981). «La presencia del realisme: l'arquitectura com a experiència interior», Quaderns d'Arquitectura i Urbanisme, 147, octubre, pp. 1-8. [https://www. raco.cat/index.php/QuadernsArquitecturaUrbanisme/article/view/198892]

Martín Gaite, Carmen (1993). «Todo es un cuento roto en Nueva York», en Después de todo. Poesía a rachas, Madrid, Hiperión, pp. 88-92.

— (1997). Edward Hopper. Habitación de hotel, Madrid, Fundación Colección Thyssen-Bornemisza.

— (2005). Visión de Nueva York, Madrid, Círculo de Lectores-Siruela.

Morier, Henri (1989). «Hypotypose», en Dictionnaire de Poétique et de Rhétorique, Paris, PUF, pp. 524-534.

OAtes, Joyce Carol (1989). «Edward Hopper's Nighthawks, 1942», en The Time Traveler, New York, Dutton, pp. 40-42.

Riffaterre, Michael (1994). «L'Ilusion d'ekphrasis», en Gisèle MathieuCastellani, La Pensée de l'image: signification et figuration dans le texte et dans la peinture,Vincennes, Presses Universitaires de Vincennes, pp. 211-229. 
- (2002). «Ekphrasis Lyrique», The Romanic Review, 93, 1-2 (January-March), pp. 201-216.

Rodríguez, Pedro (2018). «De lejos», $A B C, 5$ de julio, p. 30.

Sala Valldaura, Josep Maria (2009). «Del estar al ser: El don de la ignorancia, de José Corredor-Matheos», en Estudios sobre la poesía de José Corredor-Matheos, eds. Jesús Barrajón Muñoz y María Rubio Martín, Madrid, Calambur, pp. 331-344.

Strand, Mark (2008). Hopper, trad. y pról. Juan Antonio Montiel, Barcelona, Lumen.

Vega-Sampayo, Elena (2008). La poesía esencial de José

Corredor-Matheos, León, Universidad de León.

Xirau, Ramón (1993). Palabra y silencio, México D. F., Siglo

Veintiuno Editores-El Colegio Nacional. 